\title{
Psychotherapy of Childhood Anxiety Disorders: A Meta-Analysis
}

\author{
Tina In-Albon Silvia Schneider \\ Department of Clinical Child and Adolescent Psychology, University of Basel, Basel, Switzerland
}

\author{
Key Words \\ Child psychotherapy evaluation - Childhood anxiety \\ disorders · Treatment evaluation
}

\begin{abstract}
Background: The present study compared the efficacy of psychotherapy for childhood anxiety disorders (excluding trials solely treating post-traumatic stress disorder or obsessive-compulsive disorder). Methods: The metaanalysis included studies that met the basic CONSORT (consolidated standards of reporting trials) criteria. Several outcome variables (e.g. effect sizes, percentage of recovery) were analyzed using completer and intent-totreat analyses during post-treatment and follow-up assessment. Twenty-four studies published by March 2005 were included in this meta-analysis. Results: In all the included studies, the active treatment condition was cognitive-behavioral. The overall mean effect of treatment was 0.86 . No differences in outcome were found between individual and group treatments or child- and family-focused treatments. Follow-up data demonstrated that treatment gains were maintained up to several years after treatment. Conclusions: These findings provide evidence that anxiety disorders in children can be treated efficaciously. The gathered data support the clinical utility of cognitive-behavioral therapy in this regard. Randomized controlled trial studies investigating treatments other than cognitive-behavioral therapy are missing.
\end{abstract}

Copyright $@ 2007$ S. Karger AG, Basel

\section{KARGER \\ Fax +4161306 1234 \\ E-Mail karger@karger.ch}

www.karger.com
(C) 2007 S. Karger AG, Basel

0033-3190/07/0761-0015\$23.50/0

Accessible online at: www.karger.com/pps

\section{Introduction}

Anxiety disorders are the most prevalent mental disorders not only of adulthood but also of childhood and adolescence $[1,2]$. Trait anxiety seems to have increased greatly [3] and new research shows that childhood anxiety disorders are important risk factors for the development of mental disorders in adulthood, including anxiety disorders, depression and substance abuse [4-6]. The development and dissemination of efficacious treatments are, therefore, essential.

Clinical research on psychotherapy for anxiety disorders in children has advanced considerably in recent years. Different research groups have conducted several randomized controlled trials (RCTs) and substantial progress has been made in treating anxiety disorders in children and adolescents. However, these studies need to be summarized and discussed.

Meta-analyses represent an empirical approach to evaluating psychotherapy research. For a review of strengths and limitations of meta-analyses, see Sensky [7]. First meta-analyses have been published examining the efficacy of child and adolescent psychotherapies in general; yet further specific analyses of anxiety disorders were not the aim of these studies. Casey and Berman [8] reported an overall outcome effect size of 0.74 for child psychotherapy ( $\mathrm{n}=75$; studies published from 1952 to 1983) and an average treatment versus control effect size of 1.16 for phobias ( $\mathrm{n}=9$ studies). Weisz et al. [9] aggre- 
gated the effects of 39 treatment-control comparisons and reported a mean overall effect size of 0.79 for child psychotherapy ( $\mathrm{n}=163$; studies published from 1958 to 1984) and a mean effect size of 0.74 for phobias and anxiety.

A meta-analysis by Weisz et al. [10] produced an effect size of 0.60 ( $\mathrm{n}=16$ studies) for phobias and anxiety and an overall effect size of 0.54 ( $n=150$; studies published from 1967 to 1993). An examination of the different types of therapies used in these studies showed that most were behavioral therapies. In addition, effects were more robust for behavioral than nonbehavioral treatments.

A major limitation of previously published meta-analyses is the inclusion of studies which did not require the establishment of diagnoses on the basis of DSM or ICD criteria. Furthermore, these meta-analyses did not include studies published after 1993. However, in the last 10 years, substantial progress has been made regarding psychotherapy research in the area of childhood anxiety disorders.

In order to improve the quality of reports using RCTs and to comprehend the results of RCTs, the consolidated standards of reporting trials (CONSORT) were developed. The CONSORT criteria checklist contains recommendations for four stages of a trial (enrolment, intervention allocation, follow-up, and analysis). According to current guidelines $[11,12]$ (http://www.consort-statement.org) and the fact that in recent years, several methodologically rigorous child and adolescent anxiety treatment outcome studies have been completed, the purpose of this paper was to provide a comprehensive meta-analysis of child and adolescent psychotherapy outcomes for anxiety disorders, including only studies that meet basic methodological criteria. Just recently, an extensive review by Compton et al. [13] summarized RCTs on anxiety and depression and concluded that cognitive-behavioral therapy (CBT) is currently the treatment of choice for anxiety and depression in children and adolescents [see also 14]. However, this review did not include any statistical analyses summarizing the results of these studies and did not analyze different treatment settings, which could be relevant regarding treatment outcome. Therefore, the present study means to close this gap and summarize the overall effect sizes of recently published RCTs, including analyses of different treatment settings in regard to treatment outcome. The data are aggregated from published studies in the field and multiple outcome variables are reported including effect sizes of several treatment settings (e.g. individual vs. group treatment or child- vs. family-fo- cused treatment), recovery rates (both completer and intent-to-treat), sustained recovery rates and the results of follow-up assessments.

\section{Method}

\section{Literature Search}

In this meta-analysis, we included only published, peer-reviewed psychotherapy outcome studies in English and German. The literature search was conducted in PsycINFO and Medline (= PubMed) using the following key words: 'childhood', 'children', 'anxiety disorders', 'specific phobia', 'simple phobia', 'social phobia', 'panic disorder', 'separation anxiety disorder', 'generalized anxiety disorder', 'overanxious disorder', 'avoidant disorder', 'therapy', 'outcome', and 'treatment'. We also included psychotherapy studies that were listed in the reference sections of the papers we collected after the initial computer search and conducted an Internet search. This literature search produced a total of 36 treatment studies. Obsessive-compulsive disorder (OCD) and post-traumatic stress disorder (PTSD) will not be addressed in this meta-analysis because both basic research and psychotherapy research of these two disorders differ substantially from childhood anxiety disorders mentioned above. In this regard, there is an ongoing discussion whether OCD should even be assigned to anxiety disorders (see ICD-10). For separate reviews of psychotherapy research in OCD and PTSD, see Cartwright-Hatton et al. [14], Cohen et al. [15], Franklin et al. [16] and Simons et al. [70].

\section{Inclusion Criteria}

All studies included in this meta-analysis were required to have investigated the efficacy of a specific treatment for anxiety disorders in children against a control condition or alternative credible psychotherapeutic treatment. Participants (i.e., the children who were treated) had to have met DSM or ICD diagnostic criteria for a principal anxiety disorder, and participants had to have been randomly assigned to either treatment or control conditions (i.e., an RCT). In accordance with the CONSORT guidelines, the authors of the studies were required to have written a standard treatment protocol. In order to facilitate computation of effect sizes, studies were included only if they reported means and standard deviations of the outcome measures as well as sample sizes at each assessment time point. We excluded studies in which treatment groups had fewer than 10 patients (lack of power), single case studies, subclinical cases and psychopharmacological studies. Studies had to have been published by March 2005. All decisions were made a priori, before examining any individual studies. These several steps produced a pool of 24 studies for further analyses. An overview of all the studies is in Appendix 1. The treatment orientation of the excluded studies was primarily CBT, except the chart review of Target and Fonagy [18], which involved a psychodynamic approach.

\section{Effect Size}

The effect size (Cohen's d) is an index of the size and direction of treatment effects. Cohen [19] suggests that an effect size of 0.20 may be considered a small effect, 0.50 a medium effect, and 0.80 a large effect. 
We computed different effect sizes for both treatment and control conditions including a global effect size and separate effect sizes for the three most commonly used outcome measures (see below). Effect sizes were calculated for pre-/post-treatment and for pre-follow-up assessments. Within each study, effect size values were averaged across all outcome variables to an overall effect size (one effect size per study). In a second step, these effect sizes were averaged across all studies (global effect size). Specific effect sizes were calculated separately for the most commonly used measurements, i.e. Revised Children's Manifest Anxiety Scale (RCMAS), Fear Survey Schedule for Children-Revised (FSSC-R), and Children's Depression Inventory (CDI) within each study and then averaged across all studies. In addition, 95\% confidence intervals were computed for the effect sizes of each category. When the associated confidence intervals do not include 0 , this indicates that the average effect size is significantly greater than zero at $\mathrm{p}<0.05$. Q statistic was calculated to determine whether the effect size data from the studies are homogeneous. If the studies share a common effect size, the value of $\mathrm{Q}$ will be nonsignificant. Fail-safe number statistics were calculated to check the robustness of the findings and whether significant mean effect sizes might have been inflated by a publication bias [20]. The fail-safe number informs about the number of file drawer studies required to bring the mean effect size down to a defined level. Orwin [21] adopted Rosenthal's formula for probabilities to effect sizes $\mathrm{d}: \mathrm{n}_{\mathrm{fs}}=\left[\mathrm{n}_{\text {total }}\left(\right.\right.$ mean $\left.\left._{\mathrm{d}}-\mathrm{d}_{\text {crit }}\right)\right] / \mathrm{d}_{\text {crit }}$.

In additional analyses, we distinguished between child- and family-focused treatments. Child-focused treatment was defined as the treatment which focuses on the children and in which the parents are either not included at all or minimally involved (i.e., in three sessions or fewer). Family-focused treatment was defined as the treatment in which parents are actively involved in the treatment process for more than three sessions, the nature and extent of parental involvement being clearly described in the treatment procedure section of the study.

\section{Recovery}

Percent recovered is an essential index of a clinically significant change. However, most of the studies reported recovery rates based on the percentage recovered compared to those who completed treatment rather than those who entered treatment (i.e., intent-totreat). Intent-to-treat analyses produce a more conservative estimate of recovery by answering the question: 'Of those patients who entered in and began treatment, what percentage is likely to recover?' We will report recovery rates for both completer and intentto-treat analyses.

\section{Follow-Up Data}

Follow-up data provide an accurate picture of the efficacy of treatment and its lasting effects.

\section{Measures}

In order to establish diagnoses before and after treatment and at follow-up and to determine diagnostic recovery, most studies used the Anxiety Disorders Interview Schedule for Children (ADIS) [22]. The ADIS is a structured diagnostic interview consistent with the DSM-IV criteria. It assesses child functioning (anxiety, mood, and externalizing disorders) in separate interviews: one with the child and one with the parents. The ADIS contains a Clinician Severity Rating, a scale ranging from 0 (absent) to 8 (very severe) that represents the degree of symptom severity and interference of di- agnosis assigned by the interviewer based on clinical information provided by the interview. The interview has good interrater reliability for the child and the parent interview, adequate test-retest reliability [23], and is sensitive to treatment effects in studies with youths with anxiety disorders [24].

\section{Child Measures}

The RCMAS [25] measures chronic anxiety and is one of the most frequently used anxiety self-report measures for children. The RCMAS consists of 37 items, each one rated as true or false. There has been extensive work supporting the RCMAS's validity and reliability [25]. Significant correlations have been found between RCMAS scores and other self-report measures of anxiety and related constructs such as depression [26].

The FSSC-R consists of 80 items and assesses specific fears in children [27]. The child rates his or her level of fear on a three-point Likert scale. Ollendick [27] reported solid internal consistency and adequate test-retest reliability.

The CDI consists of 27 items and assesses cognitive, affective, and behavioral symptoms of depression. For each item, children are given three choices from which they select the one which best describes themselves over the past 2 weeks. The CDI has good internal consistency, moderate test-retest reliability [28] and correlates in the expected direction with measures of related constructs such as self-esteem, negative cognitive attributes, and hopelessness [29].

\section{Procedure}

We assessed the following major variables from each study: sample size, means and standard deviations of outcome measures, percentage of children who completed treatment, pre-/post-treatment and treatment-control effect sizes, and percentage of children who recovered after treatment, both for those who entered (intentto-treat) and for those who completed treatment. For follow-up, we assessed the same variables provided that such data were available.

\section{Effect Size Calculation}

The pre-/post-treatment and pre-follow-up effect sizes were calculated as follows:

$$
d_{e s}=\frac{M_{t 1}-M_{t 2}}{\sqrt{\frac{\left(N_{t 1}-1\right) S D_{t 1}^{2}+\left(N_{t 2}-1\right) S D_{t 2}^{2}}{N_{t 1}+N_{t 2}-2}}}
$$

where $M$ is the mean of the measurement, $t 1$ represents the pretreatment assessment, $t 2$ represents the post-treatment or follow-up assessment, $N$ is the sample size, and $S D$ the standard deviation [30].

To investigate the treatment-control effect size we used the following formula:

$$
d_{e s}=\left[\frac{\left(M_{\text {TGpost }}-M_{\text {CGpost }}\right)}{S D_{\text {pooledpre }}}\right]-\left[\frac{\left(M_{\text {TGpre }}-M_{\text {CGpre }}\right)}{S D_{\text {pooledpre }}}\right]
$$

where $M$ is the mean of the measurement, $T G$ represents the treatment group, $C G$ represents the control group, and $S D_{\text {pooledpre }}$ is the pooled within-group standard deviation. 


\section{Results}

Data from 24 clinical trials were included in this metaanalysis. In all 24 studies, the active treatment condition was cognitive-behavioral. Twelve studies included individual treatment and fifteen included group therapy. Seventeen studies included child-focused treatment and 14 included family-focused treatment. Sixteen studies had a waiting list control condition; the remaining included an alternative therapy as a control condition. The length of treatment ranged from 3 to 18 sessions, with an average length of 12.3 sessions. The total number of patients across all studies was 1,275, and the mean age of participants was 10.9 years (range: $6-18$ years). The vast majority of studies evaluated the efficacy of psychotherapy in children with anxiety disorders. Only the study of Ginsburg and Drake [31] examined the feasibility and effectiveness of a school-based group CBT for anxiety disorders with low-income African-American adolescents. The study conducted by Baer and Garland [32] evaluated a CBT program in a community psychiatric setting.

\section{Interventions Used by the Studies}

Most programs were designed to target the child's anxiety using a mixture of exposure techniques $(90.5 \%)$, cognitive restructuring strategies $(66.7 \%)$, relaxation techniques $(52.4 \%)$, and positive self-talk (38.1\%). In regard to parents, the majority of family-focused treatment studies used the following interventions: teaching parents to deal and cope with child anxiety and its related behaviors, teaching communication and problem-solving skills, and managing the parents' own anxiety. Interventions used in the attention placebo control condition were designed to provide the child and the parents with a broad range of information about anxiety (education support), but no encouragement or instructions were offered to confront feared situations [33-36].

\section{Exclusion Criteria Used by the Studies ${ }^{1}$}

Many studies excluded children with psychotic symptoms $(72.2 \%)$ and mental retardation (50\%). Most studies (77.8\%) excluded children who were currently involved in psychosocial or psychopharmacological treatment. However, more recent studies [32, 37-39] did include children who were on psychopharmacological medica-

\footnotetext{
1 The exclusion criteria for each study included in this meta-analysis can be requested from the authors.
}

tion, as long as they maintained a constant dosage on the same medication throughout the duration of the study.

\section{Completion Rates}

Most children who entered treatment $(n=1,275)$ completed it $(n=1,080 ; 84.7 \%)$. Completion rates were $85.8 \%$ for group treatment, $84.9 \%$ for individual therapy, $82.9 \%$ for family-focused treatment, and $84.9 \%$ for child-focused treatment. Thus, very similar completion rates were found across all modes of treatment.

\section{Effect Sizes}

Active Treatment vs. Waiting List (Global and

Specific Effect Sizes)

The mean overall pre-/post-treatment effect size across all treatments was $d=0.86(95 \% C I=0.69-1.03 ; n=24)$, whereas the effect size for the waiting list control group was $d=0.13(95 \% \mathrm{CI}=0.03-0.24 ; \mathrm{n}=16)$. The specific effect sizes for the three most common treatment outcome measurements (RCMAS, FSSC-R, and CDI) were as follows: pre-/post-treatment effect size in the treatment condition was $0.83(95 \% \mathrm{CI}=0.64-1.02)$ for trait anxiety (RCMAS) and $0.85(95 \% \mathrm{CI}=0.45-1.24)$ for phobic anxiety (FSSC-R). In the control condition, effect sizes were $0.22(95 \% \mathrm{CI}=0.08-0.35$; RCMAS) and $0.32(95 \% \mathrm{CI}=$ 0.11-0.54; FSSC-R). Furthermore, symptoms of depression $(\mathrm{CDI})$ improved significantly $(\mathrm{d}=0.70 ; 95 \% \mathrm{CI}=$ $0.54-0.86)$ in the treatment condition compared to the waitlist control condition $(d=0.20 ; 95 \% C I=0.07-0.33)$. The mean overall treatment versus control effect size across all active treatments averaged $0.66(95 \% \mathrm{CI}=$ 0.36-0.96) at the post-treatment assessment. The $t$ test with independent samples revealed a significant difference between treatment versus control effect size $[\mathrm{t}(37)=$ 6.92, $\mathrm{p}=0.00]$.

Homogeneity of effect sizes for post-test data was tested. The resulting $\chi^{2}$ value was nonsignificant $\left[\chi^{2}(24)=\right.$ $25.08, p=0.20$ ], indicating that the assumption of homogeneity for the post-test effect sizes cannot be rejected.

The fail-safe number of this study suggests that 79 file drawer studies with effect sizes of zero are necessary to reduce the effect size of 0.86 to a mean effect size of 0.20 . To reduce the effect size of 0.86 to a mean effect size of $0.50,17$ studies of zero effect would be necessary.

\section{Follow-Up}

Of the 24 outcome studies, 16 reported short-term follow-up assessment data. On average, short-term followup assessments occurred 10.4 months after the end of treatment. The effect size for pre-follow-up was 1.36 (95\% 
Table 1. Pre-/post-treatment and follow-up effect sizes (d) and 95\% confidence intervals for individual vs. group therapy and for child-focused vs. family-focused therapy

\begin{tabular}{|c|c|c|c|c|}
\hline & $\begin{array}{l}\text { Pre-/ } \\
\text { post-treatment }\end{array}$ & $95 \% \mathrm{CI}$ & Follow-up & $95 \% \mathrm{CI}$ \\
\hline Individual therapy & $1.00(n=6)$ & $0.80-1.21$ & $1.04(\mathrm{n}=5)$ & $0.61-1.47$ \\
\hline Group therapy & $0.97(n=10)$ & $0.62-1.32$ & $1.64(n=4)$ & -0.84 to 4.11 \\
\hline Child-focused therapy & $0.91(n=16)$ & $0.73-1.1$ & $1.30(\mathrm{n}=10)$ & $0.75-1.85$ \\
\hline Family-focused therapy & $0.83(\mathrm{n}=10)$ & $0.42-1.25$ & $1.38(\mathrm{n}=9)$ & $0.44-2.3$ \\
\hline
\end{tabular}

Some studies investigated more than one treatment setting.
Table 2. Percentage of patients who recovered of those who completed or entered treatment

\begin{tabular}{|c|c|c|c|c|}
\hline & \multicolumn{2}{|c|}{$\begin{array}{l}\text { Percent recovered of } \\
\text { completed }\end{array}$} & \multicolumn{2}{|c|}{$\begin{array}{l}\text { Percent recovered of } \\
\text { entered (intent-to-treat) }\end{array}$} \\
\hline & mean $\pm \mathrm{SD}$ & $\mathrm{n}$ & mean $\pm \mathrm{SD}$ & $\mathrm{n}$ \\
\hline Individual treatment & $72.1 \pm 14.48$ & 11 & $57.3 \pm 17.42$ & 7 \\
\hline Group treatment & $66 \pm 8.84$ & 12 & $53.2 \pm 7.36$ & 6 \\
\hline Child-focused treatment & $64.1 \pm 10.46$ & 12 & $54.4 \pm 12.95$ & 11 \\
\hline Family-focused treatment & $76.9 \pm 7.88$ & 10 & $65.2 \pm 14.76$ & 9 \\
\hline All active treatments & $68.9 \pm 11.75$ & 21 & $55.4 \pm 13.43$ & 13 \\
\hline Waiting list control group & $12.9 \pm 9.8$ & 15 & - & - \\
\hline
\end{tabular}

There is a significant difference between the treatment and waiting list control groups.
$\mathrm{CI}=0.78-1.94 ; \mathrm{n}=16$ ). There are 3 long-term follow-up studies: the 6-year follow-up study by Barrett et al. [40], the 3.4-year study by Kendall and Southam-Gerow [41] and the 7.4-year study by Kendall et al. [42]. The longterm effect size for the study by Kendall and SouthamGerow [41] was 0.61. The effect size for the 6-year followup study of Barrett et al. [40] was 0.82. Finally, the effect size for the 7.4-year follow-up study by Kendall et al. [42] was 1.13 for child report and 1.54 for parent report.

\section{Treatment Setting (Global Effect Sizes)}

Table 1 displays the mean overall pre-/post-treatment and pre-follow-up effect sizes for the outcome studies by treatment type. Group and individual treatments were equally effective in reducing children's symptoms. The mean overall treatment versus control pre-/post-treatment effect sizes were $0.52(95 \% \mathrm{CI}=0.04-0.99)$ for individual therapy and $0.61(95 \% \mathrm{CI}=0.44-0.79)$ for group therapy. The $t$ test with independent samples revealed a nonsignificant difference $[\mathrm{t}(11)=0.33, \mathrm{p}=0.75]$.

As shown in table 1, the pre-/post-treatment effect size for child-focused treatments was similar to the effect size of treatments involving parents. The mean overall treatment versus control pre-/post-treatment effect sizes were $0.53(95 \% \mathrm{CI}=0.30-0.77)$ for child-focused therapy and $0.63(95 \% \mathrm{CI}=1.3-0.58)$ for family-focused therapy. This difference was not significant $[\mathrm{t}(21)=0.26, \mathrm{p}=0.79]$.

\section{Placebo Condition vs. Waiting List (Global Effect}

Sizes)

We compared waiting list control conditions with active, nonspecific control conditions, and the pre-/posttreatment effect sizes were $0.13(95 \% \mathrm{CI}=0.03-0.24$; $\mathrm{n}=16)$ for waiting list and $0.58(95 \% \mathrm{CI}=-1.6$ to 1.3 ; $\mathrm{n}=4$ ) for attention placebo control.

\section{Percent Recovered}

Table 2 displays the percentage of patients who recovered from those who completed and those who entered treatment. Across all active treatments, $68.9 \%$ of children who completed therapy no longer met the diagnostic criteria for their principal pretreatment anxiety disorder compared to only $12.9 \%$ of children who were assigned to a waiting list. The $t$ test with independent samples re- 
vealed a significant difference between treatment versus control group after treatment with respect to children without anxiety diagnosis $[\mathrm{t}(34)=15.06, \mathrm{p}<0.00]$. At the follow-up assessment, the recovery rate of children who completed treatment increased slightly to $72 \%$.

Individual and group therapies showed comparable recovery rates of $72.1 \%$ and $66 \%$, respectively. For the intent-to-treat sample, the overall recovery rate after treatment was $55.4 \%$. Intent-to-treat recovery rates were similar for individual (57.3\%) and group (53.2\%) therapy. Child- and family-focused treatment showed recovery rates of $64.1 \%$ and $76.9 \%$, respectively. For the intent-totreat sample, the recovery rate after treatment for childfocused treatment was $54.4 \%$ and $65.2 \%$ for family-focused treatment. Because of a lack of the majority of treatment studies to report the number of dropouts in the waiting list conditions, the intent-to-treat recovery rate could not be investigated.

\section{Discussion}

In the present study, we examined $24 \mathrm{RCT}$ s out of a pool of 36 treatment outcome studies on anxiety disorders in children and adolescents. The results of the present study indicate that treatment produces acute effects, which reflect substantial symptom improvement. The current findings are consistent with previous meta-analyses and provide convergent evidence that CBT is effective for children with anxiety disorders.

The robust effects of therapy are reflected in the pre-/ post-treatment effect sizes of 0.86 in the treatment and 0.13 in the waiting list control conditions. Of the children included in our study who completed treatment, $68.9 \%$ recovered to the extent that they no longer met criteria for their principal pretreatment anxiety diagnosis. In comparison, only $12.9 \%$ of waiting list participants recovered. Furthermore, the fail-safe number statistic shows that 79 file drawer studies with effect sizes of zero are needed to reduce this effect size to a mean effect size of 0.20 .

Symptom improvements following treatment occurred not only for anxiety but also for depression. The treatment versus control effect size was 0.66 . Previous metaanalytic estimates reported similar [10] or higher pre-/ post-treatment effect sizes $[8,9]$ in general child and adolescent psychotherapy.

Interestingly, the attention placebo control condition reached a pre/post-treatment effect size of $0.58(n=4)$. Compared to the overall pre-/post-treatment effect size of the active treatment condition (0.86), the effect size for the active control condition is quite high. Four studies included in our meta-analysis compared their active interventions with an attention placebo control condition [33-36]. However, only the study of Beidel et al. [33] and Muris et al. [36] used a strict placebo condition consisting of study skills, test-taking strategies and emotional disclosure, which led to a significant treatment vs. placebo effect. The two other studies included psychoeducation on anxiety comparable to information given in CBT programs, which were equally effective as the active treatments. Thus, these results could imply that improvement in childhood anxiety disorder can be achieved purely with psychoeducation on anxiety, without explicit instructions for exposures. This interesting issue requires further investigation.

Treatment outcome studies comparing the efficacy of child-alone therapy to interventions involving both children and parents have found conflicting results. As in the meta-analysis of Casey and Berman [8], we did not find a difference between the two types of treatment. The mean treatment versus control effect size was 0.53 for child-focused therapy and 0.63 for family-focused treatment. To date, there is no clear empirical evidence indicating who might benefit more from one type of therapy over the other. Some data suggest that younger children and children with parents who have an anxiety disorder themselves may benefit more from a combined child and parent treatment than from a child-alone therapy [43, 44]. However, in the study by Barrett et al. [43], the relative superiority of CBT plus family anxiety management condition compared to $\mathrm{CBT}$ alone at the 12-month posttreatment assessment disappeared at the 6-year follow-up assessment [40]. Likewise, the results of other studies [45-47] suggest that for some children, a child-alone approach may be sufficient for anxiety symptom reduction. Further research must examine the role of parental involvement in treatment for children with different anxiety disorders and identify child and family characteristics that will enable clinicians to assign anxious children to either a child-alone intervention or a combined parentchild intervention.

While earlier studies established the efficacy of individual therapy in treating child anxiety disorders, the results of a number of recent trials suggest that group treatment may be equally efficacious [38, 48]. In the present study, the mean effect sizes for group and individual therapy were comparable. These results should nevertheless be interpreted with caution. A number of group treatment studies in our meta-analysis included family-focused in- 
terventions $(n=7)$, making it difficult to disentangle the effects of group therapy and family involvement. Though Muris et al. [38] have recently demonstrated the similarity in outcomes of group and individual treatment without parental involvement in either condition, future research should continue to investigate this question while controlling the overlap of family-focused and group treatment settings.

Weisz et al. [9, 10] and Kazdin et al. [49] reported in their meta-analyses that only around one third of all published treatment outcome studies reported data from follow-up assessments. Recently published studies seem to have improved in this regard, as $16(66.7 \%)$ of the 24 outcome studies included in our meta-analysis reported follow-up data. In our meta-analysis, the mean pre-followup effect size was 1.36 , suggesting that treatment gains were well maintained. Furthermore, $72 \%$ of the children did not meet the criteria for their principal pretreatment diagnosis at follow-up. These results are consistent with three long-term follow-up studies [40-42], which have demonstrated that the effects of child anxiety treatments are relatively stable and long-lasting (up to 7.4 years).

With the exception of five studies that investigated the efficacy of psychotherapy for social phobia [32, 33, 46, $50,51]$, none of the other treatment studies differentiated between the different types of anxiety disorders. In fact, these studies tested general treatments for anxiety disorders in groups of children with different anxiety disorders (separation anxiety disorder, generalized anxiety disorder, specific phobia, social phobia). However, RCT studies with a focus on specific anxiety disorders, in particular separation anxiety disorder, generalized anxiety disorder and specific phobia, are needed to complement the previous global approaches.

All studies included in the meta-analysis investigated the efficacy of CBT. Thus, non-CBT outcome studies that fulfill the methodological criteria required by CONSORT are still missing. In the literature search for the present study, we found a chart review of child psychoanalysis and psychotherapy of children with emotional disorders [18], which reported an improvement rate of $47.2 \%$ in a large child sample $(n=352)$. However, this study did not meet the inclusion criteria for our meta-analysis (see Appendix 2).

It has to be considered that the studies included in this meta-analysis demonstrate efficacy of psychotherapy for anxious children; however, effectiveness has to be proven. Therefore, now that CBT trials are found to be successful, it is important to extend studies to the clinical settings. Baer and Garland [32] investigated a pilot study of community-based cognitive-behavioral group therapy for adolescents with social phobia. Although the sample size $(n=12)$ was small, the study provides support for the use of simplified cognitive-behavioral interventions in community psychiatric settings. Similar conclusions can be drawn from the study of Ginsburg and Drake [31] that evaluated the feasibility and effectiveness of a schoolbased group treatment for anxiety disorders with AfricanAmerican adolescents. For the evaluation of the presented results, general limitations regarding meta-analyses have to be considered. The reported effect sizes only provide information about how much the patients improved after therapy compared to their values before therapy. Thus, the effect sizes do not provide information regarding symptom severity and functional level after therapy compared to healthy control participants.

Reported effect sizes are based entirely on self-report measures, due to the fact that parent and teacher reports were not regularly assessed. However, the gold standard in assessing efficacy of psychotherapy in children and adolescents should be the inclusion of self-reports as well as parent and teacher reports [71]. Further psychotherapy research should take this into consideration in order to get a sound and accurate description of therapy outcome.

Knowing how to treat childhood anxiety disorders is important. Such knowledge both helps ease the suffering of children and contributes to the reduction and prevention of future suffering as adults. As we work toward improving psychotherapy for childhood anxiety disorders, we must especially focus on helping those children for whom existing therapies continue to produce less than optimal outcomes.

\section{Acknowledgements}

This research was supported by a Swiss National Science Foundation scholarship to Tina In-Albon (PBBS1-102350) and by a grant of the Swiss National Science Foundation to Silvia Schneider (SNF PP001-68701). The authors thank David A. Moscovitch, Michael K. Suvak, Department of Psychology, Boston University, and Andrea H. Meyer, University of Basel. 


\section{Appendix 1}

Studies Included in the Meta-Analysis

\begin{tabular}{|c|c|c|c|c|c|c|c|c|}
\hline Study & $\mathrm{n}$ & Age & Mode & Diagnosis & Weeks & $\begin{array}{l}\text { Com- } \\
\text { pleted, } \%\end{array}$ & $\mathrm{FU}$ & $\begin{array}{l}\text { Pre-/post-treatment effect size (d) } \\
\text { per treatment condition }{ }^{4}\end{array}$ \\
\hline $\begin{array}{l}\text { Baer and Garland } \\
\quad[32]\end{array}$ & 12 & $13-18$ & $\mathrm{Gr}^{1}$ & SoP & 12 & 36 & - & SPAI: 1.20 \\
\hline Barrett [48] & 60 & $7-14$ & $\mathrm{Gr}^{1,2}$ & $\mathrm{SAD}, \mathrm{OAD}, \mathrm{SoP}$ & 12 & 83 & 12 months & $\begin{array}{l}\text { FSSC-R Ch: } 1.54, \text { FSSC-R Fam: } \\
2.37\end{array}$ \\
\hline $\begin{array}{l}\text { Flannery-Schröder } \\
\text { et al. [52] }\end{array}$ & 37 & $8-14$ & Ind $+\mathrm{Gr}^{1}$ & GAD, SAD, SoP & 18 & 76 & 3 months & Ind: 1.26, Gr: 0.73 \\
\hline Gallagher et al. [51] & 23 & $8-11$ & $\mathrm{Gr}^{1}$ & SoP & 3 & 50 & 3 weeks & 0.36 \\
\hline Ginsburg et al. [31] & 12 & $14-17$ & $\mathrm{Gr}^{1}$ & GAD, SPP, AG, SoP & 10 & 75 & - & SCARED: 0.27 \\
\hline Hayward et al. [50] & 35 & $14-18$ & $\mathrm{Gr}^{1}$ & SoP & 16 & 81 & 12 months & SPAI: 1.10 \\
\hline Kendall et al. [54] & 94 & $9-13$ & Ind $^{1}$ & $\mathrm{SAD}, \mathrm{OAD}, \mathrm{AD}$ & 16 & 80 & $\begin{array}{l}12 \text { months; Kendall } \\
\text { et al. [42]: } 7 \text { years }\end{array}$ & 1.08 \\
\hline King et al. [55] & 34 & $5-15$ & $\operatorname{Ind}^{2}$ & SAD, OAD, SoP, SPP, CD & 4 & 100 & 3 months & 1.37 \\
\hline Last et al. [34] & 56 & $6-17$ & $\operatorname{Ind}^{2,3}$ & Schoolpho ${ }^{4}$ & 12 & 73 & 1 month & $\begin{array}{l}\text { STAIC-T CBT: } 0.57 \text {, STAIC-T ES: } \\
1.33\end{array}$ \\
\hline Manassis et al. [37] & 78 & $8-12$ & Ind $+\mathrm{Gr}^{2}$ & GAD, SAD, SPP, SoP, PD & 12 & - & - & SASC Gr: 0.21, SASC Ind: 0.43 \\
\hline $\begin{array}{l}\text { Mendlowitz et al. } \\
\text { [39] }\end{array}$ & 62 & $7-12$ & $\mathrm{Gr}$, act $\mathrm{tx}^{1,2}$ & - & 12 & 91 & - & Ch: $0.26, \mathrm{~Pa}: 0, \mathrm{Ch}+\mathrm{Pa}: 0.33$ \\
\hline Muris et al. [38] & 36 & $8-13$ & $\mathrm{Gr}+\mathrm{Ind}^{1}$ & GAD, SAD, SoP & 12 & 100 & - & STAIC Ind: 0.82, STAIC Gr: 1.08 \\
\hline Muris et al. [36] & 30 & $9-12$ & $\mathrm{Gr}^{1,3}$ & GAD, SAD, SoP & 12 & 80 & - & STAIC: 1.38 \\
\hline Nauta et al. [47] & 79 & $7-18$ & Ind $^{1,2}$ & SAD, SoP, GAD, PD & 12 & 96 & 3 months & SCAS Ch: 1.13, SCAS Pa: 0.65 \\
\hline Rapee [56] & 95 & $7-16$ & $\mathrm{Gr}^{2}$ & SAD, GAD, SoP & 12 & - & 12 months & 0.81 \\
\hline
\end{tabular}

$\mathrm{SAD}=$ Separation anxiety disorder; $\mathrm{GAD}=$ generalized anxiety disorder; $\mathrm{OAD}=$ overanxiety disorder; $\mathrm{SoP}=$ social phobia; $\mathrm{SPP}=$ specific phobia; $\mathrm{PD}=$ panic disorder; $\mathrm{AG}=$ agoraphobia; $\mathrm{CD}=$ conduct disorder; Schoolpho = school refusal; $\mathrm{Gr}=$ group treatment; Ind = individual treatment; act tx = active placebo treatment; SPAI = Social Phobia and Anxiety Inventory; SCARED = Screen for Childhood Anxiety Related Emotional Disorders; SCAS = Spence Child Anxiety Scale; STAIC-T = State-Trait Anxiety Inventory for Children; SASC = Social Anxiety Scale for Children; ES = education support; SC = exposure-based cognitive self-control; $\mathrm{CM}=$ exposure-based contingency management; $\mathrm{PAM}=$ parental anxiety management; $\mathrm{Tb}=$ testbuster.

${ }^{1}$ Child-focused treatment.

${ }^{2}$ Family-focused treatment.

${ }^{3}$ Attention-placebo control group.

${ }^{4}$ Effect sizes are indicated for outcome measure RCMAS, when not otherwise specified. 


\section{References}

1 Anderson JC, Williams S, McGee R, Silva W: DSM-III disorders in preadolescent children. Arch Gen Psychiatry 1987;44:69-76.

$\checkmark 2$ Steinhausen HC, Metzke CW, Meier M, Kannenberg R: Prevalence of child and adolescent psychiatric disorders: the Zürich epidemiological study. Acta Psychiatr Scand 1998;98:262271.

$>3$ Twenge JM: The age of anxiety? Birth cohort change in anxiety and neuroticism, 19521993. J Pers Soc Psychol 2000;79:10071021.

-4 Brückl TM, Wittchen H-U, Höfler M, Pfister H, Schneider S, Lieb R: Childhood separation anxiety and the risk of subsequent psychopathology: results from a community study. Psychother Psychosom 2007;76:47-56.

$\checkmark 5$ Woodward LJ, Fergusson DM: Life course outcomes of young people with anxiety disorders in adolescence. J Am Acad Child Adolesc Psychiatry 2001;40:1086-1093.

6 Goodwin RD, Fergusson DM, Horwood LJ: Panic attacks and the risk of depression among young adults in the community. Psychother Psychosom 2004; 73:158-165.

7 Sensky T: The effectiveness of cognitive therapy for schizophrenia: what can we learn from the meta-analyses? Psychother Psychosom 2005; 74:131-135.

8 Casey RJ, Berman JS: The outcome of psychotherapy with children. Psychol Bull 1985;98: 388-400.

9 Weisz JR, Weiss B, Alicke MD, Klotz ML: Effectiveness of psychotherapy with children and adolescents: a meta-analysis for clinicians. J Consult Clin Psychol 1987;55:542-549.

$>10$ Weisz JR, Weiss B, Han S, Granger DA, Morton $\mathrm{T}$ : Effects of psychotherapy with children and adolescents revisited: a meta-analysis of treatment outcome studies. Psychol Bull 1995; 117:450-468.

11 Altman DG: Better reporting of randomized controlled trials: the CONSORT statement (editorial). BMJ 1996;31:570-571.

-12 Altman DG, Schulz KF, Moher D, Egger M, Davidoff F, Elbourne D, Gotzsche PC, Lang $\mathrm{T}$ : The revised CONSORT statement for reporting randomized trials: explanation and elaboration. Ann Intern Med 2001;134:663694.

-13 Compton SN, March JS, Brent D, Albano AM, Weersing VR, Curry J: Cognitive-behavioral psychotherapy for anxiety and depressive disorders in children and adolescents: an evidence-based medicine review. J Am Acad Child Adolesc Psychiatry 2004;43:930-959.

$\checkmark 14$ Cartwright-Hatton S, Roberts C, Chitsabesan $\mathrm{P}$, Fothergill C, Harrington R: Systematic review of the efficacy of cognitive behaviour therapies for childhood and adolescent anxiety disorders. Br J Clin Psychol 2004;43:421-436.
15 Cohen J, March JS, Berliner L: Treatment of PTSD in children and adolescents; in Foa EB, Davidson J, Keane T (eds): Effective Treatments for PTSD. New York, Guilford, pp 106138.

16 Franklin ME, Rynn M, March JS, Foa EB: Obsessive-compulsive disorder; in Hersen M (ed): Clinical Behavior Therapy: Adults and Children. New York, Wiley, pp 276-303.

17 Abramowitz JS, Whiteside SP, Deacon BJ: The effectiveness of treatment for pediatric obsessive-compulsive disorder: a meta-analysis. Behav Ther 2005;3:55-63.

18 Target M, Fonagy P: Efficacy of psychoanalysis for children with emotional disorders. J Am Acad Child Adolesc Psychiatry 1994;33:361371.

19 Cohen J: A power primer. Psychol Bull 1992; 112:155-159.

20 Rosenthal R: Meta-Analytic Procedure for Social Research. Beverly Hills, Sage, 1984.

21 Orwin RG: A fail safe $N$ for effect size in metaanalysis. J Educ Stat 1983;8:157-159.

22 Silverman WK, Albano AM: The Anxiety Interview Schedule for DSM-IV, Child and Parents Versions. Albany, Graywind, 1996.

23 Albano AM, Silverman WK: Clinicians Guide to the Anxiety Disorders Interview Schedule for DSM-IV, Child Version. Boulder, Graywind, 1996.

24 Silverman WK, Kurtines WM, Ginsburg GS, Weems CF, Lumpkin PW, Carmichael DH Treating anxiety disorders in children with group cognitive-behavioral therapy: a randomized clinical trial. J Consult Clin Psychol 1999; 67:995-1003.

25 Reynolds CR, Richmond BO: Revised Children's Manifest Anxiety Scale (RCMAS) Manual. Los Angeles, Western Psychological Service, 1985

26 Rabian B: Revised children's manifest anxiety scale; in Keyser DJ, Sweetland RC (eds): Test Critiques. Austin, Pro-Ed, pp 593-599.

27 Ollendick TH: Reliability and validity of the Revised Fear Survey Schedule for Children (FSSC-R). Behav Res Ther 1983;21:685-692.

28 Kovacs M: Rating scales to assess depression in school aged children. Acta Paedopsychiatr 1981;46:305-315.

29 Kazdin AE, French H, Unis A, Esveldt-Dawson K, Sherick R: Hopelessness, depression, and suicidal intent among psychiatrically disturbed children. J Consul Clin Psychol 1983; 51:504-510.

30 Cohen J: Statistical Power Analysis for the Behavioral Sciences, ed 2. Hillsdale, Erlbaum, 1988.

31 Ginsburg GS, Drake KL: School-based treatment for anxious African-American adolescents: a controlled pilot study. J Am Acad Child Adolesc Psychiatry 2002;41:768-775.

32 Baer S, Garland EJ: Pilot study of communitybased cognitive behavioral group therapy for adolescents with social phobia. J Am Acad Child Adolesc Psychiatry 2005;44:258-264.
33 Beidel DC, Turner SM, Morris TL: Behavioral treatment of childhood social phobia. J Consult Clin Psychol 2000;68:1072-1080.

34 Last CG, Hansen C, Franco N: Cognitive-behavioral treatment of school phobia. J Am Acad Child Adolesc Psychiatry 1998;37:404411.

35 Silverman WK, Kurtines WM, Ginsburg GS, Weems CF, Rabian B, Serafini LT: Contingency management, self-control, and education support in the treatment of childhood phobic disorders: a randomized clinical trial. J Consult Clin Psychol 1999;67:675-687.

36 Muris P, Meesters C, van Melick: Treatment of childhood anxiety disorders: a preliminary comparison between cognitive-behavioral group therapy and a psychological placebo intervention. J Behav Ther Exp Psychiatry 2002; 33:143-158.

>37 Manassis K, Mendlowitz SL, Scapillato D, Avery D, Fiksenbaum L, Freire M, Monga S, Owens M: Group and individual cognitive-behavioral therapy for childhood anxiety disorders: a randomized trial. J Am Acad Child Adolesc Psychiatry 2002;41:1423-1430.

-38 Muris P, Mayer B, Bartelds E, Tierney S, Bogie $\mathrm{N}$ : The revised version of the Screen for Child Anxiety Related Emotional Disorders (SCARED-R): treatment sensitivity in an early intervention for childhood anxiety disorders. Br J Clin Psychol 2001;40:323-336.

39 Mendlowitz SL, Manassis K, Bradley S, Scapillato D, Miezitis S, Shaw BF: Cognitive-behavioral group treatments in childhood anxiety disorders: the role of parental involvement. J Am Acad Child Adolesc Psychiatry 1999;38: 1223-1229.

40 Barrett PM, Duffy Al, Dadds MR, Rapee RM: Cognitive-behavioral treatment of anxiety disorders in children: long-term (6-year) followup. J Consult Clin Psychol 2001;69:135-141.

41 Kendall PC, Southam-Gerow MA: Long-term follow-up of a cognitive-behavioral therapy for anxiety-disordered youth. J Consult Clin Psychol 1996;64:724-730.

42 Kendall PC, Safford S, Flannery-Schröder E, Webb A: Child anxiety treatment: outcomes in adolescence and impact on substance abuse and depression at 7.4 year follow-up. J Consult Clin Psychol 2004;72:276-287.

43 Barrett PM, Dadds MR, Rapee RM: Family treatment of childhood anxiety: a controlled trial. J Consult Clin Psychol 1996;64:333342 .

44 Cobham VE, Dadds MR, Spence SH: The role of parental anxiety in the treatment of childhood anxiety. J Consult Clin Psychol 1998;66: 893-905.

45 Heyne D, King NJ, Tonge BJ, Rollings S, Young D, Pritchard M, Ollendick TH: Evaluation of child therapy and caregiver training in the treatment of school refusal. J Am Acad Child Adolesc Psychiatry 2002;41:687-695. 
46 Spence SH, Donovan C, Brechman-Tooussaint $\mathrm{M}$ : The treatment of childhood social phobia: the effectiveness of a social skills training-based, cognitive-behavioral intervention, with and without parental involvement. J Child Psychol Psychiatry 2000;41:713-726.

-47 Nauta MH, Scholing A, Emmelkamp PMG, Minderaa RB: Cognitive-behavioral therapy for children with anxiety disorders in a clinical setting: no additional effect of a cognitive parent training. J Am Acad Child Adolesc Psychiatry 2003;42:1270-1278.

-48 Barrett PM: Evaluation of cognitive-behavioral group treatments for childhood anxiety disorders. J Clin Child Psychol 1998;27:459468.

-49 Kazdin AE, Bass D, Ayers WA, Rodgers A: Empirical and clinical focus of child and adolescent psychotherapy research. J Consult Clin Psychol 1990;58:729-740.

50 Hayward C, Varady S, Albano AM, Thienemann M, Henderson L, Schatzberg AF: Cognitive-behavioral group therapy for social phobia in female adolescents: results of a pilot study. J Am Acad Child Adolesc Psychiatry 2000;39: $721-726$.

-51 Gallagher HM, Rabian BA, McCloskey MS: A brief group cognitive-behavioral intervention for social phobia in childhood. J Anxiety Disord 2004; 18:459-479.

52 Flannery-Schroeder EC, Kendall PC: Group and individual cognitive-behavioral treatments for youth with anxiety disorders: a randomized clinical trial. Cogn Ther Res 2000;24: 251-278.

53 Kendall PC: Treating anxiety disorder in children: results of a randomized clinical trial. J Consult Clin Psychol 1994;62:100-110.

-54 Kendall PC, Flannery-Schrieder E, PanichelliMindel SM, Southam-Gerow M, Henin A, Warman M: Therapy for youths with anxiety disorders: a second randomized clinical trial. J Consult Clin Psychol 1997;65:366-380.
55 King NJ, Tonge BJ, Heyne D, Pritchard M, Rollings S, Young D, Myerson N, Ollendick TH: Cognitive-behavioral treatment of schoolrefusing children: a controlled evaluation. J Am Acad Child Adolesc Psychiatry 1998;37: 395-403.

56 Rapee RM: Group treatment of children with anxiety disorders: outcome and predictors of treatment response. Aust J Psychol 2000;52: 125-129.

57 Silverman WK, Kurtines WM, Ginsburg GS, Weems CF, Lumpkin PW, Carmichael DH Treating anxiety disorders in children with group cognitive-behavioral therapy: a randomized clinical trial. J Consult Clin Psychol 1999; 67:995-1003.

58 Toren P, Wolmer L, Rosental B, Eldar S, Koren S, Lask M, Weizman R, Laor N: Case series: brief parent-child group therapy for childhood anxiety disorders using a manual-based cognitive-behavioral technique. J Am Acad Child Adolesc Psychiatry 2000;39:1309_ 1312.

59 Blonk RWB, Prins PJM, Sergeant JA: Cognitive-behavioral group therapy for socially incompetent children: short-term and maintenance effects with a clinical sample. J Clin Child Psychol 1996;25:215-224.

60 Crawford AM, Manassis K: Familial predictors of treatment outcome in childhood anxiety disorders. J Am Acad Child Adolesc Psychiatry 2001;40:1182-1190.

61 Eisen AR, Silverman WK: Prescriptive treatment for generalized anxiety disorder in children. Behav Ther 1998;29:105-121.

62 Howard BL, Kendall PC: Cognitive-behavioral family therapy for anxiety-disordered children: a multiple-baseline evaluation. Cogn Ther Res 1996;20:423-443.

63 Joormann J, Unnewehr S: Eine kontrollierte Studie zur Wirksamkeit einer kognitiv-verhaltenstherapeutischen Gruppentherapie bei Kindern und Jugendlichen mit Sozialer Phobie. Z Klin Psychol Psychother 2002;31:284290 .
64 Léger E, Ladouceur R, Dugas MJ, Freeston $\mathrm{MH}$ : Cognitive-behavioral treatment of generalized anxiety disorder among adolescents: a case series. J Am Acad Child Adolesc Psychiatry 2003;42:327-330.

-65 Lumpkin PW, Silverman WK, Weems CF: Treating a heterogeneous set of anxiety disorders in youths with group cognitive behavioural therapy: a partially nonconcurrent multiple-baseline evaluation. Behav Ther 2002;33: 163-177.

66 Masia CL, Klein RG, Storch EA, Corda B: School-based behavioral treatment for social anxiety disorder in adolescents: results of a pilot study. J Am Acad Child Adolesc Psychiatry 2001;40:780-786.

67 Shortt AL, Barrett PM, Fox TL: Evaluating the FRIENDS program: a cognitive-behavioral group treatment for anxious children and their parents. J Clin Child Psychol 2001;30:525535

68 Southam-Gerow MA, Kendall PC, Weersing VR: Examining outcome variability: correlates of treatment response in a child and adolescent anxiety clinic. J Clin Child Psychol 2001;30: 422-436.

69 Svensson L, Larsson A, Öst LG: How children experience brief-exposure treatment of specific phobias. J Clin Child Adolesc Psychol 2002; $31: 80-89$

70 Simons M, Schneider S, Herpertz-Dahlmann B: Metacognitive therapy for pediatric obsessive-compulsive disorder: a randomized pilot study. Psychother Psychosom, in press.

71 Kraemer HC, Measelle JR, Ablow JC, Essex MJ, Boyce WT, Kupfer DJ: A new approach to integrating data from multiple informants in psychiatric assessment and research: mixing and matching contexts and perspectives. Am J Psychiatry 2003;160:1566-1577. 